\title{
Evaluating the effects of Hong Kong-Zhuhai-Macao bridge on international air travel: demand analysis of the air-bridge-air path
}

\author{
Jing Lu and Cheng Lv \\ College of Civil Aviation, \\ Nanjing University of Aeronautics and Astronautics, \\ Nanjing 211106, Jiangsu, China \\ Email:1j_ppx@icloud.com \\ Email: lvcheng0504@nuaa.edu.cn
}

\section{Tao Feng*}

Department of the Built Environment,

Technische Universiteit,

Eindhoven $5600 \mathrm{MB}$, the Netherlands

Email: t.feng@tue.nl

*Corresponding author

\section{Zheqing Wang}

College of Civil Aviation,

Nanjing University of Aeronautics and Astronautics,

Nanjing 211106, Jiangsu, China

Email: wangzheqing@nuaa.edu.cn

\begin{abstract}
To consolidate its position as the busiest Chinese hub to Southeast Asia, Hong Kong airport is collaborating with Zhuhai airport through the Hong Kong-Zhuhai-Macao Bridge to establish an air-bridge-air path, which may potentially encourage the international business and tourism along the Belt and Road economic corridor. To predict the increased demand attracted by this path, this paper proposes a path choice model using a nested logit model, which incorporates intermodal transfers on a time-space network. The proposed model was estimated based on the data collected from a stated preference survey and was applied to forecast the geographical distribution of air passenger flow. As predicted, the air-bridge-air path improves the connection and the travel efficiency between Northwest China and Southeast Asia, indicating its contribution to develop the Belt and Road initiative. Meanwhile, some strategies for developing the flight network of Zhuhai airport are proposed, where starting up a new air route from Xining to Zhuhai is recognised as the best option according to the scenario analysis results.
\end{abstract}

Keywords: Belt and Road initiative; B\&R initiative; air-bridge-air path; timespace-network; passenger flow distribution.

Reference to this paper should be made as follows: Lu, J., Lv, C., Feng, T. and Wang, Z. (2020) 'Evaluating the effects of Hong Kong-Zhuhai-Macao bridge on international air travel: demand analysis of the air-bridge-air path', European J. International Management, Vol. 14, No. 4, pp.595-616. 
Biographical notes: Jing Lu graduated from Dalian Maritime University and obtained a BS, MS, and PhD in transportation engineering. Since 2016, she has worked at Nanjing University of Aeronautics and Astronautics in Nanjing, China. She published more than 20 papers in the field of transportation planning and management, including the following papers: An integrated Markov decision process and nested logit consumer response model of air ticket pricing, Transportmetrica A; Current and previous research interests end the paragraph; and Design of timetable for airport coach based on time-space network and passenger's trip chain, Transport. Her research interests are concentrated in simulation and deep learning application in transportation management.

Cheng Lv graduated from Nanjing University of Aeronautics and Astronautics and obtained a BS degree in Air Traffic Management. Since 2018, he is studying for a MS degree in Transportation Planning and Management at Nanjing University of Aeronautics and Astronautics in Nanjing, China. His interests include indoor localisation and discrete choice.

Tao Feng received his PhD in Urban Development (Transportation Planning) from Hiroshima University, Japan, in 2008. Before appointed as an Assistant Professor in 2013, he has been a post-doctoral researcher at TU/e. In 2017, he has been a visiting associate professor in Hiroshima University. He serves as associate editor in journal Asia Transport Studies, associate chair and scientific committee members of several international conferences. He obtained and coordinated several research projects, including DESENT, CHIPS and TERTS from Urban Europe and Interreg, and participated in many others at national and international levels. He has published more than 40 papers in refereed journals and many papers in conferences, book chapters etc.

Zheqing Wang graduated from Jiangsu University and obtained a BS degree in transportation engineering. Since 2017, she is studying for a MS degree in Transportation Planning and Management at Nanjing University of Aeronautics and Astronautics in Nanjing, China. Her interests include discrete choice simulation.

\section{Introduction}

In the past five years, due to the Belt and Road (B\&R) initiative, the cross-border trading and tourism between China and Southeast Asia have been developing and flourishing (Huang, 2016; Arase, 2015; Liu et al., 2018). In the context, a large number of airports in China began to start up direct flights to Southeast Asia for matching the air travel demand growing rapidly ( $\mathrm{Li}$ et al., 2018; Shao et al., 2018). Although passengers were delighted to see the new flights, the traditional hubs like Hong Kong airport felt threatened because their previous market may be diverted by other developing airports (Walcott and Fan, 2017; Liu et al., 2018). Hence, Hong Kong airport, which possesses the busiest flights to Southeast Asia, has a strong desire to find new markets in mainland China to consolidate its hub position (Tsui et al., 2018).

According to the statistics in Figure 1, cities in Northwest China seem to be the best choices regarding the limited flights to Southeast Asia and the constantly increasing aviation demand (up to $23.7 \%$ per year recently). However, in reality, the connections between Northwest China and Hong Kong airport are very weak at present (only five 
direct flights every day), and to make the situation worse, there might be no extra space for the new flights before the finish of the third runway in 2023. That is to say it is quite difficult for Hong Kong airport to capture the markets in Northwest China through its own efforts (Wang et al., 2017).

Figure 1 Direct flight volume from airports in China to Southeast Asia

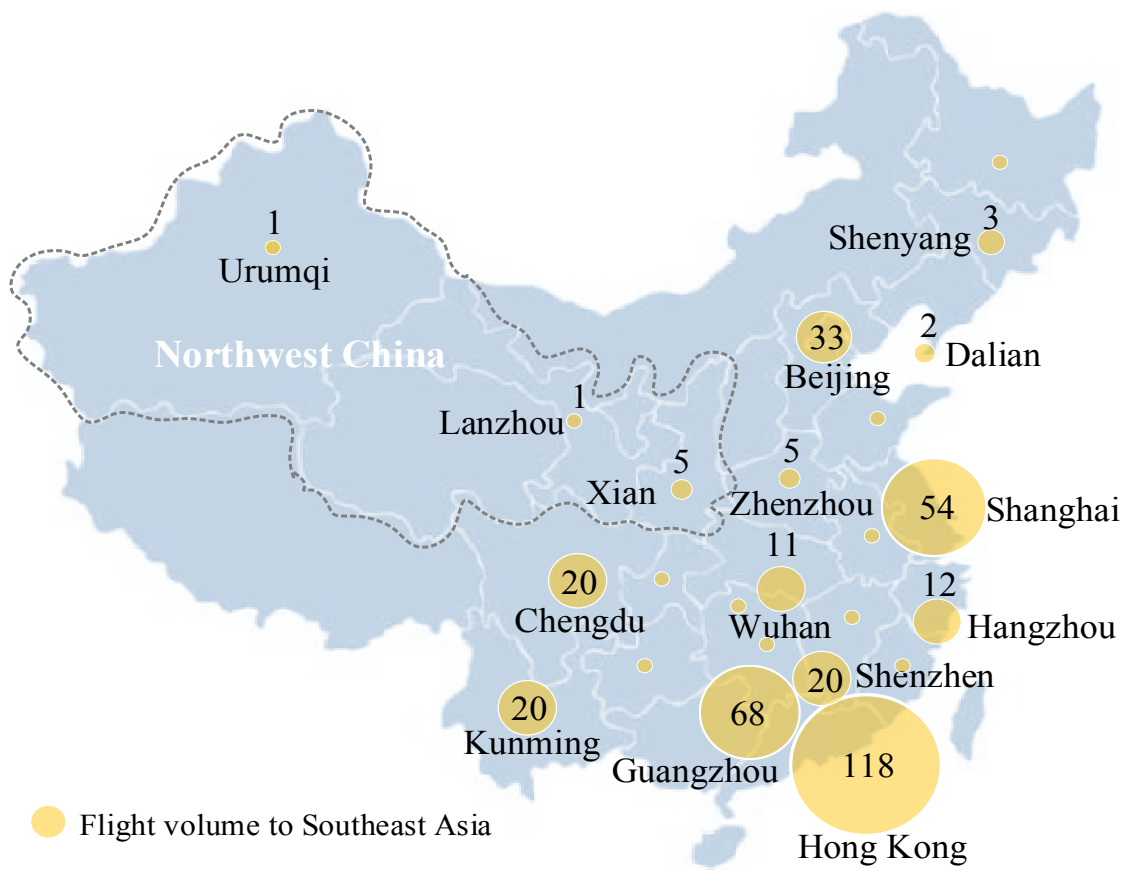

Source: Database of official airline guide (OAG)

Fortunately, because of the Hong Kong-Zhuhai-Macao Bridge (abbreviated as the Bridge), Hong Kong airport has the opportunity to approach Northwest China through a collaboration with Zhuhai airport by establishing an air-bridge-air path, as demonstrated in Figure 2. To be specific, the air-bridge-air path allows passengers to fly to Zhuhai airport first, then to use a coach to arrive at Hong Kong airport, and ultimately to take an international flight to their final destination. In that sense, Zhuhai airport acts as the gateway to Hong Kong airport, and the coach shuttling through the Bridge would help shorten the distance between them. With the path, hundreds of multi-modal connections would be created by the airlines and airports to serve the international air travel, which will, to a large extent, stimulate the bilateral business and tourism between China and Southeast Asia by providing cheap and frequent flight services.

As said above, the path brings lots of benefits, but the intricate transfers resulting in higher time costs may negatively impact passengers' choice preferences (Bliemer and Rose, 2011). Hence, if we want to push the collaboration between Hong Kong airport and Zhuhai airport, it is necessary to figure out some valuable strategies related to the airbridge-air path, and the key of the work is to model the path choice behaviour which determines the air travel demand using the path (Wadud, 2015; D’Alfonso et al., 2013). 
For the studies that analyse the path choice behaviour in the context of international air travel, most of them established their methods based on a pure aviation network (Yang et al., 2014; Gillen et al., 2015; Jiang and Zhang, 2016). However, due to the distinct differences between air-air and air-coach transfers, existing models are not suitable for predicting the choice probability of the air-bridge-air path. Meanwhile, as the alternative paths in the model should link flights, coaches and transfers in terms of time and space, it is difficult to describe them in a one-dimensional network. Therefore, a time-space network should be applied to simplify the approach (Tong et al., 2015).

Figure 2 Diagram of the air-bridge-air path

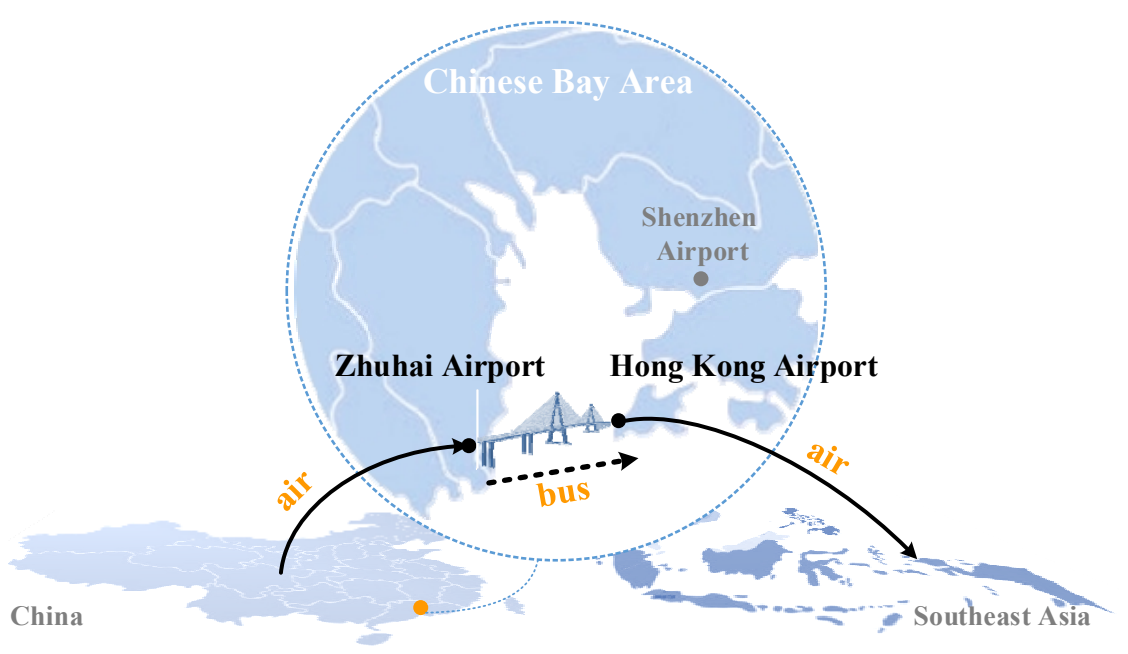

In order to predict the potential demand attracted by the air-bridge-air path, this paper proposes a path choice approach based on the nested logit model and a time-space network. As the proposed approach improves the predicting accuracy of the air passenger flow using multimodal transportation modes, it offers great value for international management with respect to the air travel demand, especially in the multi-airport region where the linkages between different travel modes have strong influences on air travel choices (Li and Sheng, 2016). From a management point of view, this can benefit the management of resources, time and space in every segment of the path. Meanwhile, the optimal management on airport operations will need the flight coordinating strategies between Hong Kong and Zhuhai airport, which may lead to a better way of collaboration.

The subsequent paper is organised as follows: Section 2 reviews pertinent studies, Section 3 introduces the path choice model and the time-space network, Section 4 describes the SP survey and the data collection, Section 5 shows the estimated results and predicts the passenger distribution pattern, Section 6 discusses the strategies for adding flights of Zhuhai airport to enhance the connection to Northwest China, and Section 7 presents the conclusions. 


\section{Literature review}

The air-bridge-air paths consist of domestic and international flights as well as landbased connections through the Hong Kong-Zhuhai-Macao Bridge. As per the report, Hong Kong Transport Department is tasked to operate a shuttle bus between Zhuhai and Hong Kong airports, and the flight schedules of the two airports would also be coordinated in the future (Shuai, 2018). Under these circumstances, Zhuhai airport would be a feeding airport that may help consolidate the hub position of Hong Kong airport in the context of the Belt and Road Initiative. Meanwhile, it also would be a very important domestic transfer hub in the multi-airport region in China's Bay Area (Sit, 2003; Loo, 2008; Sismanidou et al., 2013; Hussain et al., 2011).

Although few articles mention the air-bridge-air path, the air-rail-air path has been commonly recognised and has received more and more attention (Jiang et al., 2017; Xia et al., 2019; Li et al., 2018; D’Alfonso et al., 2016). For example, Jiang and Zhang (2014) analysed the possibility of diverting passengers from congested airports to uncongested ones using air-rail connections, which illustrates the advantages of constructing such an intermodal path. Compared to the air-rail-air path, the air-bridge-air path may be more unique, and the connections between air and land would be more flexible. For instance, different levels of shuttle services would be provided for passengers with different needs, such as a public shuttle bus, a group shuttle bus or a VIP shuttle car. Considering the differences analysed above, we need to interpret passengers' choice preferences for the air-bridge-air path.

The existing studies commonly analyse the path choice behaviour for air travel based on a pure aviation network (Hess and Polak, 2005; Loo, 2008; Yu et al., 2017), most of them concentrate on the choice of direct flights (Ishii et al., 2009; Yang and Liao, 2016), but seldom focus on the choice of connecting flights. In this sense, the most relevant researches that would be referred by us are the ones that analyse the demand assignment on hub-and-spoke networks (Wei and Hansen, 2006; Hsiao and Hansen, 2011). In the demand assignment models, passengers are assigned to different paths with the goal of realising the shortest travel time or the lowest travel cost (Fu et al., 2014). Such methods are suitable for predicting the distribution of large-scale demand on the air transportation network (Duthie et al., 2011), but ignore the choice preferences (Bowman and BenAkiva, 2001).

Therefore, we choose to use the discrete choice model, which has been proved to be effective in previous studies (Alhussein, 2011; Behrens and Pels, 2012; Drabas and Wu, 2013) for analysing the choice of the air-bridge-air path. Comparing to the choice of connecting flights, the path in our study accommodates intermodal transfers between air and coach. Therefore, besides some attributes such as departure time, in-flight time, and air ticket prices (Hess, 2007; Chang, 2013; Wan et al., 2015), we will incorporate factors related to the intermodal transfers such as coach frequency and coach price (Akar, 2013; Chiambaretto et al., 2013). Meanwhile, regarding the substitutable relationships between the different paths, the nested logit structure is employed to relax the i.i.d restriction on the choice branches in the choice model (Bliemer et al., 2009).

As the segments within a path should be connected in terms of time and space, tracking the path in two-dimensional space is very complicated. For instance, Lo et al. (2003) described the complex transfers and pointed out that modelling of transfers is very challenging. Hence, we refer to previous studies about the "time-space" network to describe the spatial and temporal characteristics of the paths in a simple manner 
(Steinzen et al., 2010). The time-space network has been widely applied in the field of flight schedule planning (Yan et al., 2006; Tang et al., 2008; Abdelghany et al., 2017), and it is reported to be advanced in transforming a two-dimensional network into a onedimensional network (Barrat et al., 2005).

\section{Modelling approach}

The goal of our approach is to predict the probability that individual $i$ chooses path $j$ $(j \in\{1, \ldots, J\})$ between origin city $o$ and destination city $d$, which is written as $P_{i j o d}$ In our study, $j$ only represents a transfer path. In the model, we assume that the demand between origin city $o$ and destination city $d$ is fixed, and we only consider the change in demand volumes on different paths for each city pair.

\subsection{Establishment of the path on a time-space network}

Path $j$ is composed of several legs, and each leg represents the flight, the coach linkage or the transfer between them. The configuration of path $j$ is shown in Figure 3, indicating an intricate procedure on a two-dimensional network. Therefore, we develop a time-space network as in Figure 4 to simplify the description of alternative paths in the path set.

Figure 3 Diagram of the configuration of path $j$

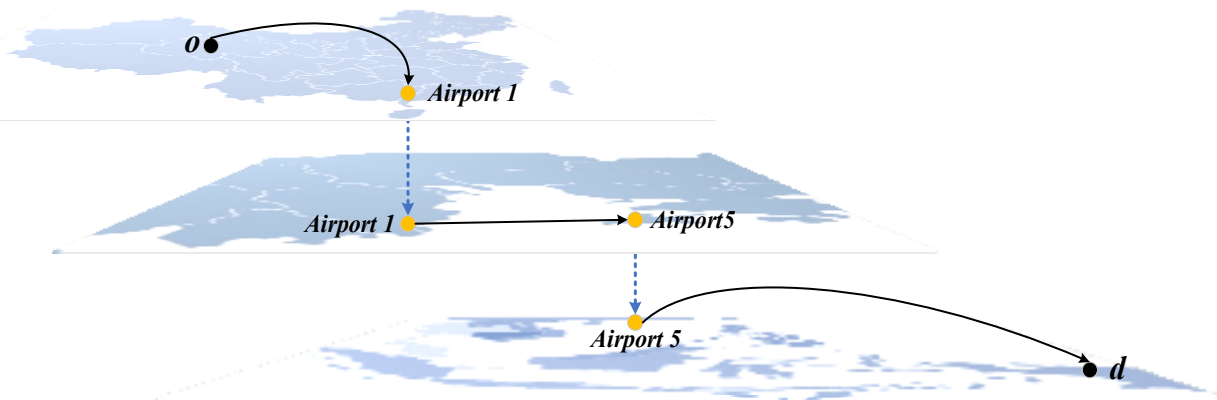

Figure 4 Diagram of path $j$ on a time-space network

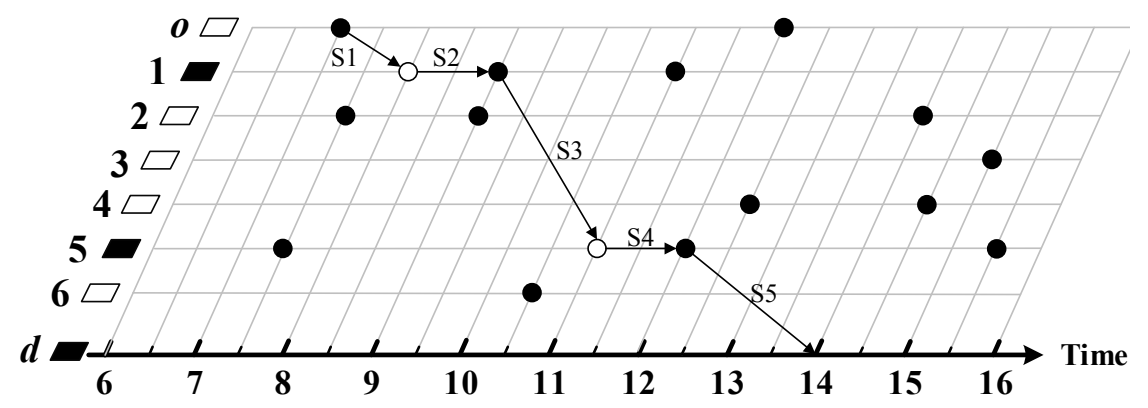


For the time-space network, the vertical axis represents airport identifiers, and parallelograms denote whether an airport has direct flights to destination $d$. The solid and hollow points represent the departure and arrival of flights or coaches, respectively. In the figure, path $j$, which has five legs (S1 to S5), will require 7 hours for passengers to travel from the origin to the destination via airport 1 and airport 5. Each alternative path $j$ has its own track on the time-space network and thus helps simplify the construction of an alternative path set for the choice model.

Furthermore, some restrictions on establishing the paths are listed in equations (1) and (2). Within path $j$, equation (1) means that the departure time of segment $s+1$ must be at least 1 hour later than the arrival time of leg $s$. Equation (2) makes sure that the departure point of leg $s+1$ is the same as the arrival point of leg $s$, indicating that passengers should transfer at the same place.

$$
\begin{aligned}
& t_{s+1 \mid j o d}-t_{s \mid j o d}^{\prime} \geq 1 \\
& m_{s+1 \mid j o d}=m_{s \mid j o d}^{\prime}
\end{aligned}
$$

\subsection{Nested Logit model}

Based on the time-space network, we should predict the preference of passenger $i$ for path $j$ between $o$ and $d\left(P_{i j o d}\right)$ using the nested logit model.

The structure of the hierarchical path choice is described in Figure 5, indicating that passengers' choice of path $j$ can be divided into two stages, determining the transfer times and choosing the transfer airports: at the top level $f$, passengers choose their preferred transfer times from $o$ to $d$. The branches in this level are one transfer and two transfers. At the second level $h$, conditional on "one transfer" being chosen, passengers choose a path from a set of options regarding air ticket price, flight time, in-flight time, transfer time, transfer mode, etc.

Figure 5 Decision tree demonstrating transfer path choice

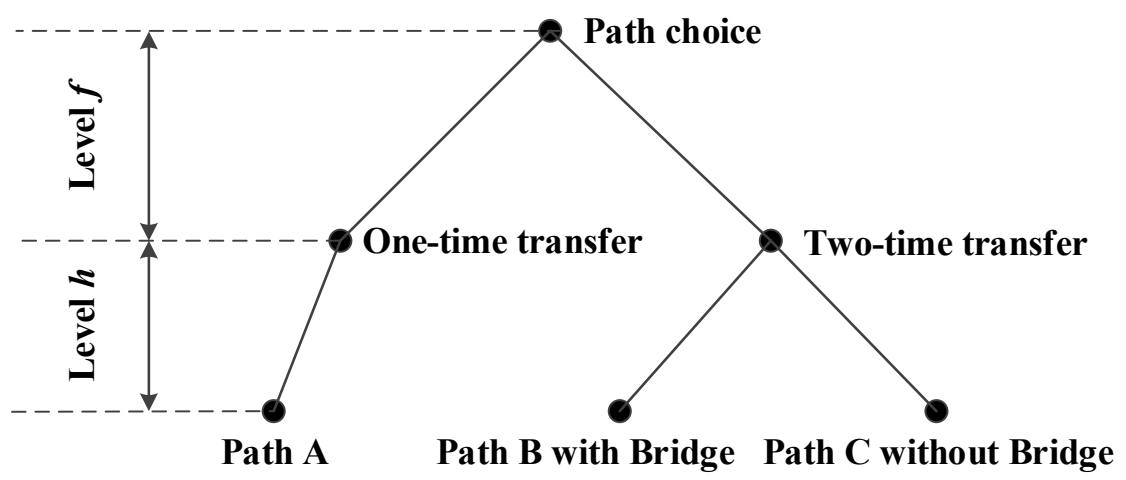

According to the decision model, a substitutable relationship exists between the alternatives in the branches "one-time transfer" and "two-time transfer". That is because the error variances in the utility functions of these alternatives are not independently and identically distributed. Therefore, to capture this choice process, we developed a discrete choice model, taking the substitutable relationship between the alternatives into account. 
In this study, we use the Nested Logit (NL) model to describe the nested structure and handle the correlation between the alternatives.

On the basis of the NL model, the utility function of each choice branch is expressed as follows:

$$
U_{i j o d}=V_{i j o d}+\varepsilon_{i j}=\alpha_{i}+\beta_{i j} z_{j o d}+\varepsilon_{i j}
$$

$U_{i j o d}$ stands for the utility of the $j$-th path cognised by passenger $i, V_{i j o d}$ is the observable portion within which $\alpha_{i}$ is the constant, $z_{j o d}$ represents the observable attributes, $\beta_{i j}$ represents the parameters for these attributes, and $\varepsilon_{i j}$ is the error variance which is assumed to be i.i.d. Accordingly, the probability of choosing path $j$ can be described as equation (4). $\theta_{f}$ is the inverse of the scale parameter $\mu_{f}$ of the branches "one-time transfer" and "two-time transfer", $0<\theta_{f}<1$, and $q$ represents the branch in level $f$.

$$
p_{i j o d}=P\left(h_{j} \mid f_{q}\right) \cdot P\left(f_{q}\right)=\frac{\exp \left(V_{i j o d} / \theta_{f}\right)}{\sum_{j=1}^{J} \exp \left(V_{i j o d} / \theta_{f}\right)} \cdot \frac{\exp \left(V_{\text {iqod }}\right)}{\sum_{q=1}^{Q} \exp \left(V_{i q o d}\right)}
$$

\section{Survey design and data collection}

\subsection{SP survey design}

To estimate the NL model, the SP survey was designed. In the survey, respondents were invited to finish four times of choice experiments. In every experiment, they were asked to select one preferred path to Southeast Asia from three alternatives including path A with one transfer, path $\mathrm{B}$ with two transfers through the Bridge and path $\mathrm{C}$ with two transfers without the Bridge. Each alternative is attributed to its corresponding variables in Table 1.

Table 1 Selected attributes and corresponding levels

\begin{tabular}{lll}
\hline & Variables & Values \\
\hline 1 & Travel purpose, (purpose) & business; leisure \\
2 & One-time-transfer ticket price, unit: RMB (dprice) & $1300 ; 1700 ; 2100 ; 2500$ \\
3 & Two-time-transfer ticket price, unit: RMB (trprice) & $300 ; 600 ; 900 ; 1200$ \\
4 & In-flight time, unit: hour (inftime) & $2.75 ; 3 ; 3.25 ; 3.75$ \\
5 & Flight departure time of first leg (fdtime) & $6: 00-8: 00,8: 00-14: 00$, \\
6 & Transfer time of the path, unit: hour (trtime) & $4: 00-19: 00,21: 00-24: 00$ \\
7 & Transfer fees of the path, unit: RMB (trfees) & $4 ; 4.5 ; 5 ; 5.5$ \\
8 & Features of transfer path, (fpath) & with trans-strait bridge; normal road \\
\hline
\end{tabular}

The first column of Table 1 shows the selected variables, and the second column describes the levels of each variable. Variable 1 helps create different scenarios (business or leisure) in which passengers would make proper choices. For the variables describing airports and flights, the values of each level were determined as close as to the reality. These attribute levels were systematically varied according to an orthogonal fraction of the full factorial design. Specifically, because one-time-transfer flights are generally 
more expensive than two-time-transfer flights, in this experiment two variables regarding 'air ticket prices' are designed with different level values. The 'transfer time' and 'transfer fees' for each alternative path are incorporated to describe the characteristics of the transfers. In addition, the variable 'features of transfer path' is set to note whether the alternative path goes through the Hong Kong-Zhuhai-Macao Bridge or not.

\subsection{Data collection for estimating SP survey}

From April to September of 2018, questionnaires were distributed through a website to respondents in 12 cities in China, including Zhuhai, Changsha, Shanghai, Nanjing, Xi'an, Beijing, Wuhan, Kunming, Lanzhou, Yinchuan, Chengdu, and Xining. The interviewed cities cover most mainland regions of China with airports, making the data set a suitable sample to test our proposed model. In addition, the company that helped conduct the survey was required to select respondents by considering the appropriate distribution for their age, income and occupation. For privacy protection, we explained the data security protocol to all the invited respondents and obtained their permission for using the survey data.

Ultimately, 994 valid questionnaires were collected, containing 3976 sets of choice data and the response rate was $85.7 \%$. The percentage of women and men in the sample is almost evenly distributed, with $45.9 \%$ women and $54.1 \%$ men. In addition, $82.39 \%$ of the sample could accept two air travel transfers, and $74.64 \%$ of the total respondents had heard the news about the Bridge, making it easy for them to imagine the scenarios in the SP survey. Moreover, the respondents' acceptable transfer times for flights and their awareness of the Bridge are shown in Figure 6.

Figure 6 Preliminary descriptive analysis. (a) Distribution of acceptable transfer instances (b) Awareness of trans-strait bridge

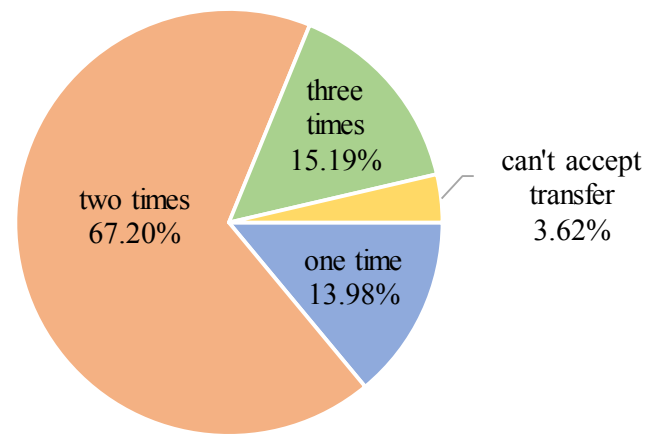

(a)

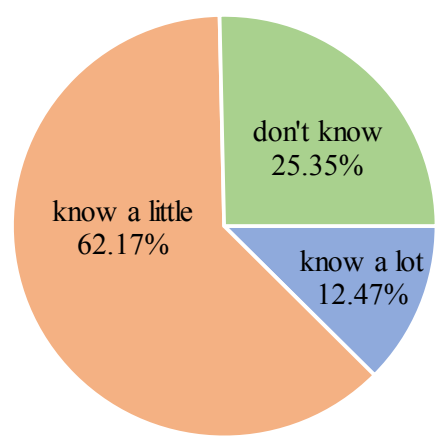

(b)

\subsection{Data collection for the time-space network}

To establish the time-space network for the choice model, we collected empirical data from airports and flights with respect to the outbound air transportation from Northwest China to Southeast Asia. The data was collected by referring to the OAG 2017 (Official Airline Guide) and the Statistical Yearbook of China Aviation 2017. Regarding the air 
travel demand from China to different cities in Southeast Asia, we chose Manila in the Philippines (with the largest increase in travel demand from China in 2017) as the destination in our research.

Then, according to the air transportation network, six airports in China were selected as the transfer airports because they have direct flights to the destinations. The selected cities are Beijing, Shanghai, Guangzhou, Xiamen, Shenzhen and Hong Kong. Meanwhile, we added Zhuhai airport and Shenzhen airport as secondary transfer airports for the air-bridge-air path. Furthermore, 15 airports in Northwest China were chosen as the origin airports including Xi'an, Lanzhou, Yinchuan, Xining, Urumqi, etc. The geographical distribution of the airports is shown in Figure 7.

Figure 7 The distribution of airports in our study

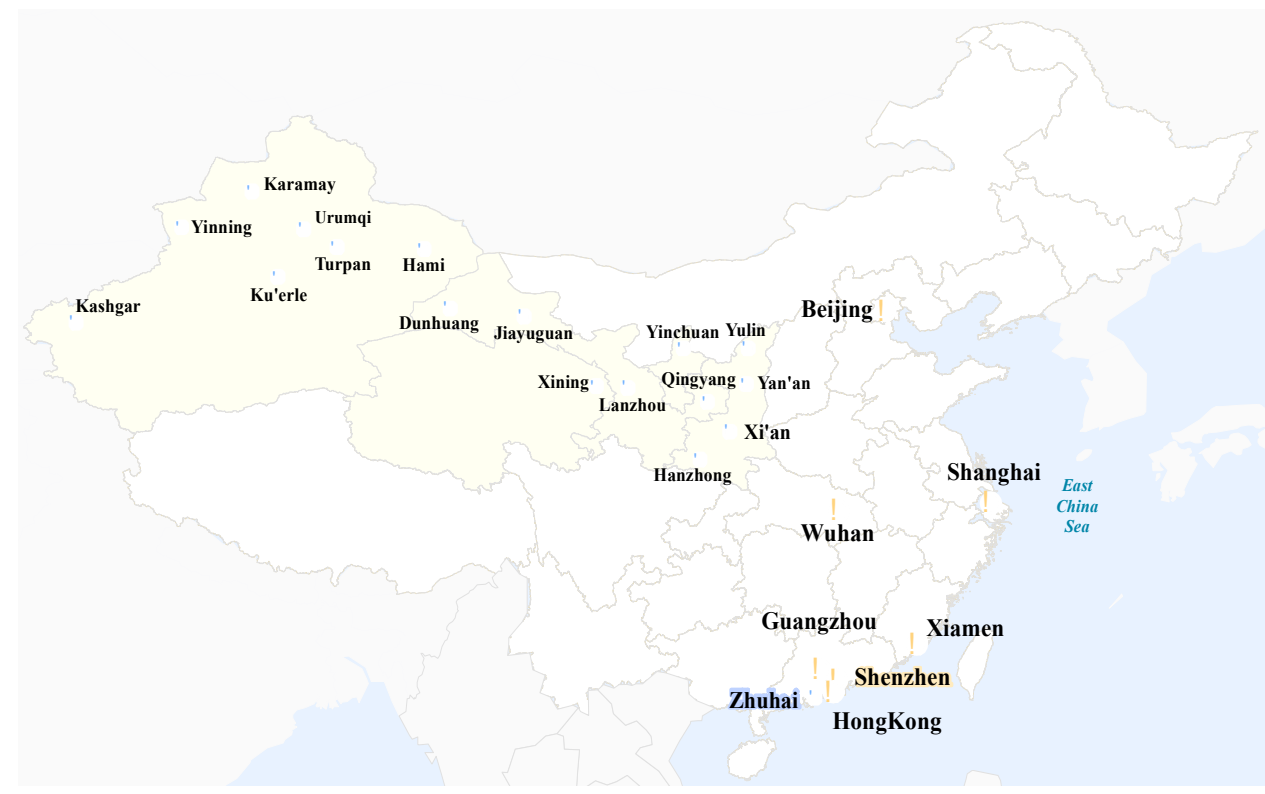

Source: Airports websites

Based on the selected airports, we filtered out related flights connecting Northwest China to Manila, all the flights (direct and transfer) are shown in Figure 8. Each flight in the figure is attributed to the service characteristics such as departure time, arrival time, inflight time, ticket price, seat volume, etc. It is clear that Xi'an, Lanzhou, Yinchuan, Xining, Urumqi, Kashgar are the key airports in Northwest China. Although Hong Kong airport has the most frequent flights to Manila, it only has two direct flights to Xi'an, revealing weak connections to Northwest China. In addition, compared to Shenzhen airport, Zhuhai airport has fewer flights to Northwest China in reality.

Then, the actual coach information from Zhuhai airport to Hong Kong airport via the Hong Kong-Zhuhai-Macao Bridge as well as the actual coach information from Shenzhen airport to Hong Kong airport was collected, and the data is shown in Table 2. 
Figure 8 Air transportation network from Northwest China to Manila

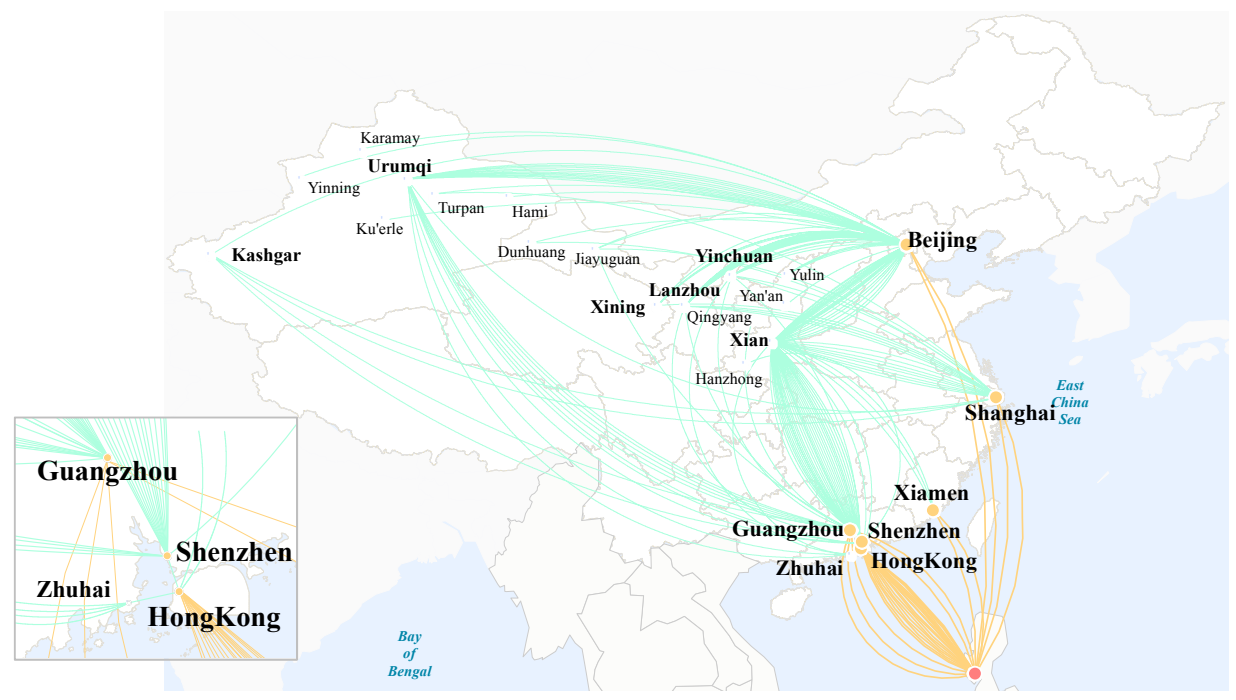

Source: Database of official airline guide (OAG)

Table 2 Service information for the buses to Hong Kong airport

\begin{tabular}{lccc}
\hline & In-vehicle time & Frequency & Price \\
\hline Zhuhai-Hong Kong & $1.5 \mathrm{~h}$ & $30 \mathrm{~min}$ & 93 \\
Shenzhen-Hong Kong & $1.5 \mathrm{~h}$ & $30 \mathrm{~min}$ & 180 \\
\hline
\end{tabular}

Source: Hong Kong airport website

Based on above data, we established 913 paths on the time-space network from Northwest China to Manila. Figure 9 shows the data related to the paths from Yinchuan airport to Manila airport. Every line of the table represents one path described by its features which are origin airport, destination airport, transfer airports, air ticket price, inflight time, flight departure time, flight arrival time, in-vehicle time, transfer fees, etc.

Figure 9 Alternative paths on the time-space network

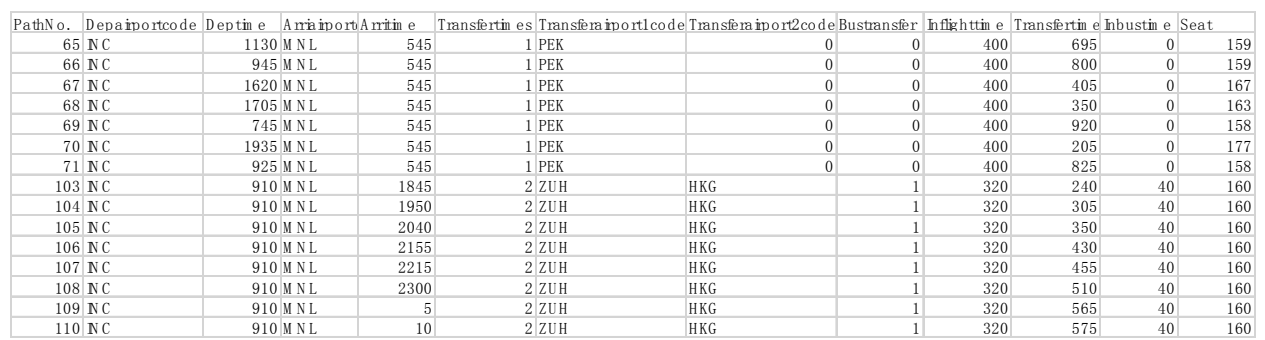

Source: Database of Official Airline Guide (OAG) 


\subsection{Data about air travel demand}

Referring to the Yearbook of China Tourism Statistics 2017 and the Report on the Big Data of China Outbound Tourism 2017, the average volume of air travel demand from Northwest China to Manila is approximately 236 people per day. As it is difficult to obtain detailed demand volume between city-pairs from the Yearbook, we choose to calculate the air travel demand of each origin city using equation (5). The first part of equation is similar to the one used by Totamane et al. (2012) in analysing air cargo transportation demand, in which the ratio of output revenue and residents' income for city A (i.e., Xi'an or Urumqi) to the total volume with the region is applied to calculate the demand volume.

$$
\text { Demand }_{\text {city A to Manila }}=\frac{\text { Output revenue }_{\text {city A }}+\text { Income }_{\text {city A }}}{\text { Output revenue }_{\text {Northwestern China }}+\text { Income }_{\text {Northwestern China }}} \times 236
$$

Figure 10 shows the percentage of air travel demand in each city to the total air travel demand from Northwest China to Manila. We can see that the distribution of air travel demand in Northwest China is uneven; most of the demand is concentrated in large cities in the Eastern part of this region. Among these cities, passengers from Xi'an comprise approximately $17.4 \%$ of the total demand. Besides, Lanzhou, Yinchuan, Urumqi and Xining are other cities with large air travel demand to Manila. When distributing the passengers in each city to the nearest airport, the air travel demand of the airports in Northwest China can be obtained, for instance the volume of passengers departing from Xi' an airport would account for $32.5 \%$ of the total demand.

Figure 10 Ratio of air travel demand of each city for flying to Manila

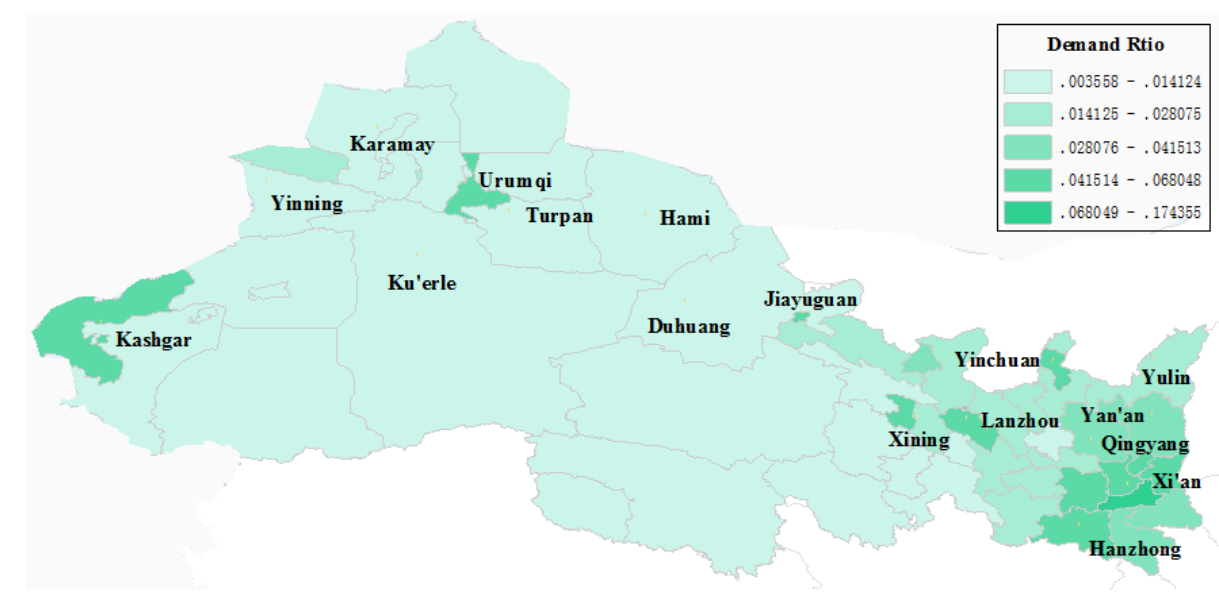

\section{Estimation results and demand forecast}

To predict the air travel demand that would be attracted by the air-bridge-air path, we first estimate the path choice model established in Section 3 based on the effect-coded data using the maximum likelihood estimation method. Then we compare the passenger 
flow distributions before and after the establishment of the air-bridge-air path, thus to know the volume of passengers switching from other hubs to Hong Kong airport.

\subsection{Estimation results of the path choice model}

The estimated results are listed in Table 4, and the last level is treated as the base level for each variable. The goodness-of-fit is satisfactory, with pseudo $\mathrm{R}^{2}$ equal to 0.312 and 0.307 . The inclusive value parameter is 0.45 and 0.42 for one-time transfer and two-time transfer, respectively. All the inclusive value parameters fall between 0 and 1 , which supports the nested Logit structure of the path choice model.

Table 4 Estimation results of path choice model

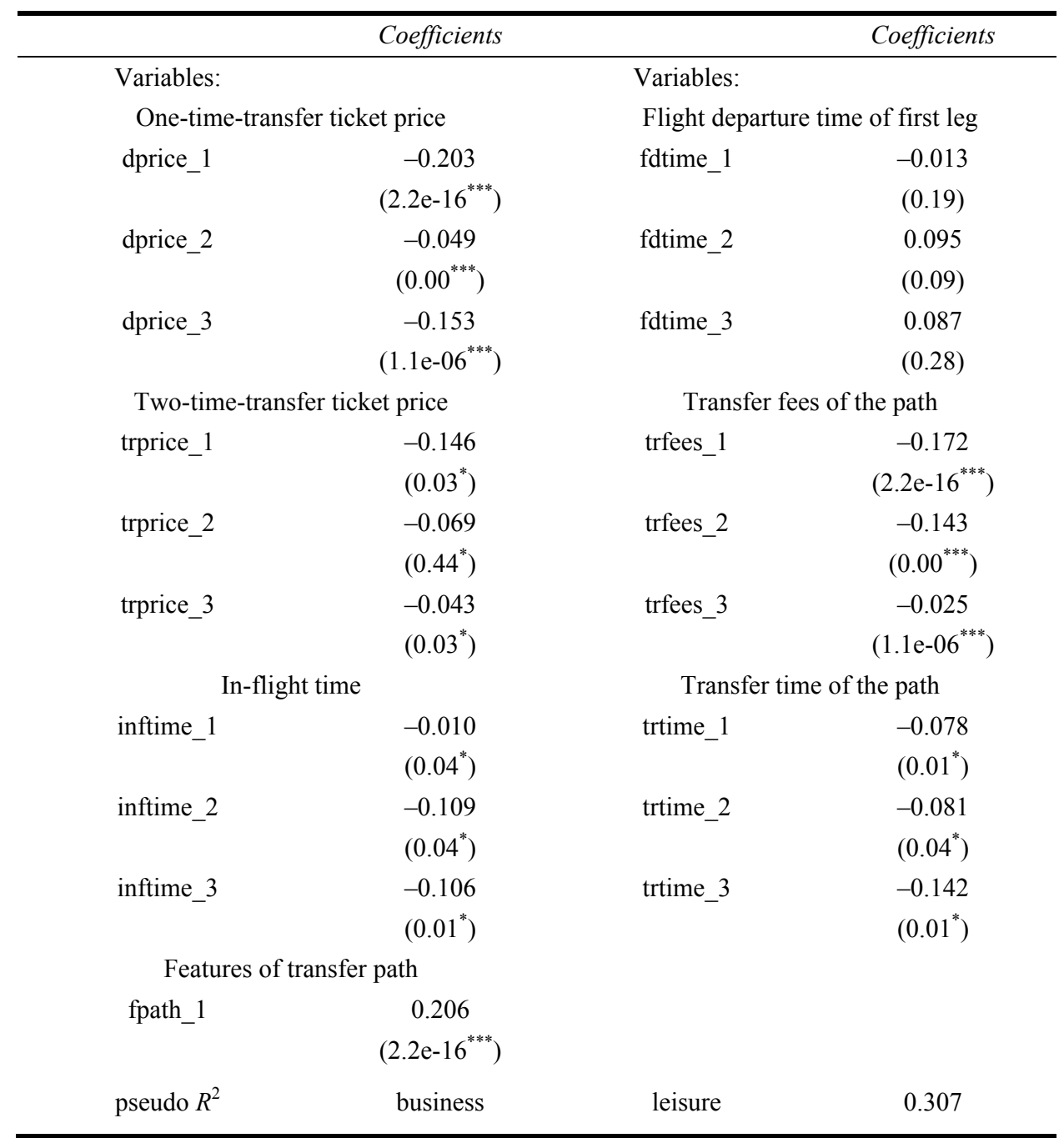

Note: $\quad * * *$ Significant at the $1 \%$ level; **Significant at the $5 \%$ level; *Significant at the $10 \%$ level 
The negative signs for 'dprice', 'trprice', 'trfees', 'inftime' and 'trtime' indicate that utility will decline with increasing ticket prices and travel time. Compared to air ticket price and in-flight time, transfer fees and transfer time have stronger negative effects on utility. Meanwhile, out of all flight departure times, 'fdtime_1' leads to higher negative effects on utility, which can be explained by the phenomenon that passengers do not prefer flights departing before 8:00 in the morning. The coefficient of 'fpath_1' is statistically significant, and its sign shows that passengers prefer the path via Hong Kong-Zhuhai-Macao Bridge due to the novelty-seeking interests.

\subsection{Geographical distribution of passenger flow}

On the basis of the empirical data and the time-space network constructed in the last section, we employ the estimated model to predict the passenger volume on each path and to further obtain passenger flow between the connected airports, finally to calculate the ratio of each flow to the total air travel demand from Northwest China to Manila. The predictions are conducted in two situations, before and after establishing the air-bridgeair path through the Hong Kong-Zhuhai-Macao Bridge. The results are illustrated in Figures 11 and 12. In the figures, the colour represents the magnitude of the ratio and the deeper colours representing higher ratios.

Figure 11 Passenger flow distribution without the air-bridge-air path

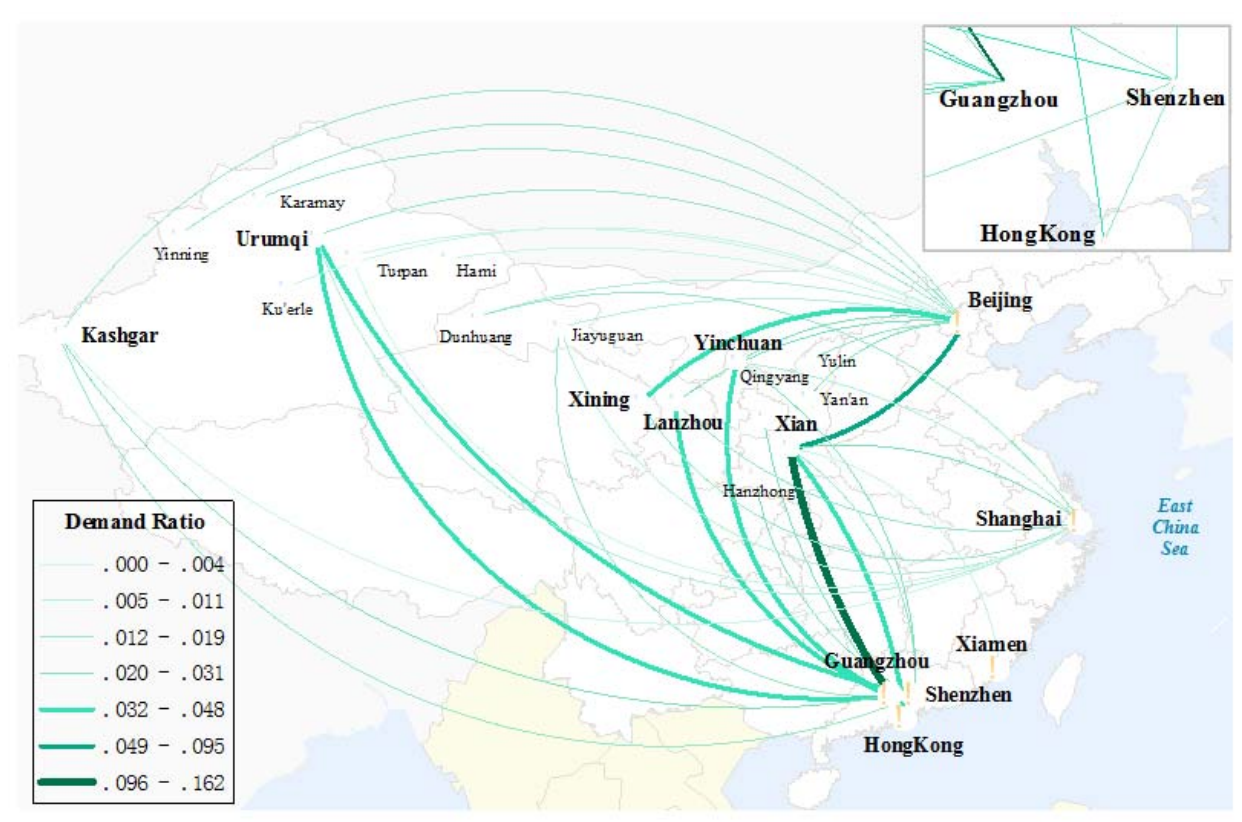

In the first situation without the air-bridge-air path, passengers choosing Guangzhou and Beijing airports comprise $49.5 \%$ and $26.1 \%$ of the total demand from Northwest China to Manila, respectively. The reasons for the success of Guangzhou airport are twofold: its developed domestic air transportation network and the well-designed temporal connection between domestic and international flights. However, although Hong Kong 
airport has the most frequent and cheapest flights to Manila, it only attracts $5.4 \%$ of the total demand due to the lack of adequate domestic flights to the target cities. In addition, only $1.7 \%$ of the passengers choose the paths linking Northwest China and Hong Kong airport via Shenzhen airport, because air tickets provided by Shenzhen airport are always more expensive than those of Guangzhou airport.

Figure 12 Passenger flow distribution with the air-bridge-air path

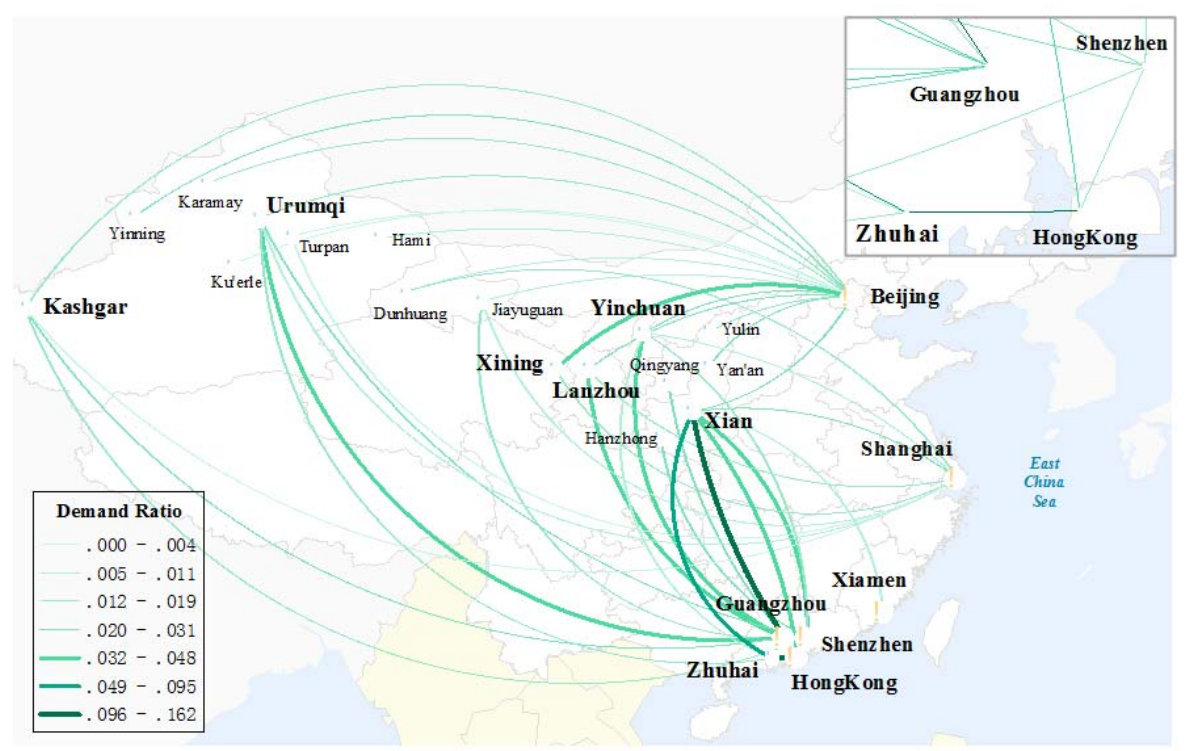

Compared to Figure 11, the passenger flow on the paths departing from Xi'an, Yinchuan and Urumqi airports begin to change when establishing the air-bridge-air path. Totally, passengers using the air-bridge-air path account for $8.6 \%$ of the air travel demand to Manila, 73\% of them switch from the path of "Xi'an-Beijing-Manila" to the path of "Xi'an-Zhuhai-Hong Kong-Manila". That is because Zhuhai airport provides much lower ticket prices to Xi'an airport, and the flights of "Hong Kong-Manila" are also cheaper, shorter and more frequent than the flights from Beijing to Manila. In the contrary, only a few passengers from Yinchuan and Urumqi change their choices in this situation, because most of them persist in choosing Guangzhou airport. In the end, the ratio of demand using Hong Kong airport grows from $5.4 \%$ to $16.7 \%$, indicating that the air-bridge-air path significantly contributes a lot to help Hong Kong airport develop the markets in Northwest China.

On the other hand, in order to analyse the effects of the air-bridge-air path on passengers' travel efficiency, we calculated the change of travel costs for all passengers in terms of money and time before and after the establishment of the air-bridge-air path. And the results show that the money and time costs decrease by $12.5 \%$ and $9.2 \%$, respectively. 


\section{Discussion}

According to the analysis in Section 5, passengers around Xi' an may have great interests to choose the air-bridge-air path, but residents from others cities do not show strong preferences to the path due to the undeveloped flight network between Zhuhai airport and other main airports in Northwest China. Therefore, in this section, we want to discuss about the strategies to develop the related flights of Zhuhai airport based on analysing the variation of demand distribution in different scenarios, thus help Hong Kong airport capture the markets of Northwest China.

\subsection{Scenario 1: adding new flights on existing air routes}

The simplest way to develop the flight network is to increase flight frequency. Here, we add two flights on the "Yinchuan-Zhuhai" air route as demonstrated in Table 5, then we calculate the change in passenger flow distributions and the results are illustrated in Figure 13.

Table 5 Information about the newly added flights from Yinchuan to Zhuhai

\begin{tabular}{ccccccc}
\hline No. & Dep airport & Dep time & Arr airport & Arr time & Seat & Price $($ RMB $)$ \\
\hline Flight 1 & Yinchuan & $7: 30$ & Zhuhai & $10: 00$ & 166 & 890 \\
Flight 2 & Yinchuan & $10: 00$ & Zhuhai & $15: 00$ & 166 & 890 \\
\hline
\end{tabular}

Figure 13 Demand flow distributions affected by the added flights. (a) Without the added flights (b) With the added flights

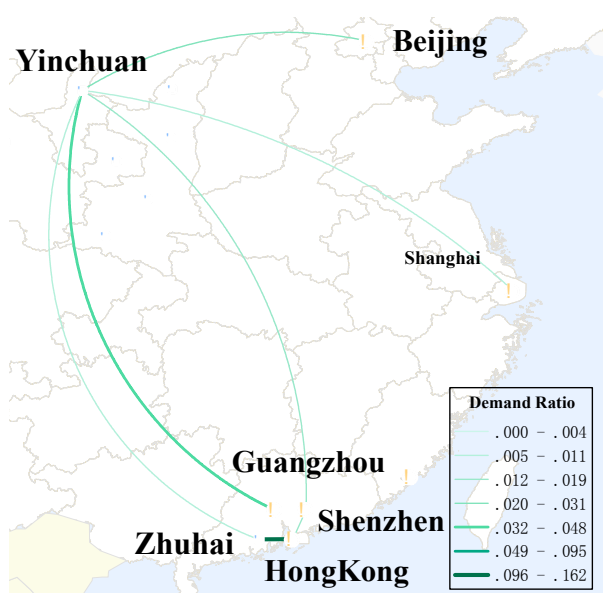

(a)

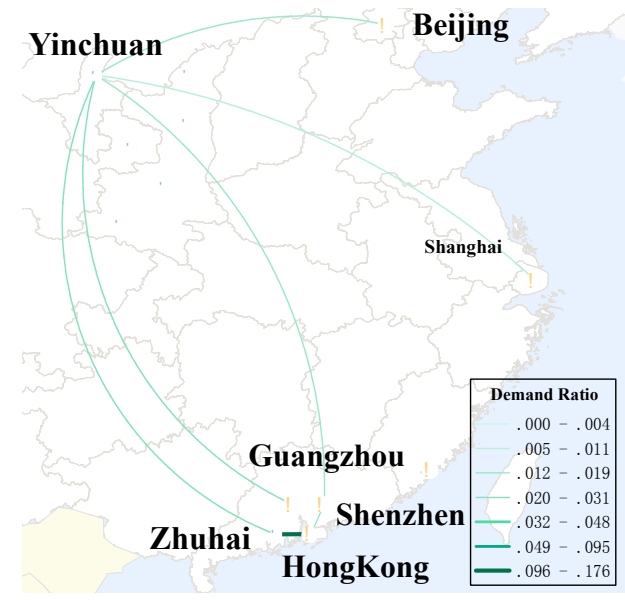

(b)

The newly added flights bring approximately 1.4\% increased demand to Hong Kong airport, and most passengers switch from Beijing and Shanghai airports. Besides, 89.6\% of the passengers who previously chose Guangzhou airport do not change their decision as Guangzhou airport has close connections with Yinchuan airport, and the ticket prices 
are almost the same as the ones provided by Zhuhai airport. Regarding the possibility of reducing ticket prices, it is not reasonable to add flights between Yinchuan and Zhuhai.

\subsection{Scenario 2: start up a new air route "Xining to Zhuhai"}

In addition to increasing flight frequency, starting up new air routes is another useful way to develop the flight network. According to the airport traffic rankings in 2017, we assume one new air route from Xining to Zhuhai is started, and the flights on the new air route are listed in Table 6 . Then, we calculate the passenger flow in this scenario, and the results are shown in Figure 14.

Table 6 Flights on the newly added air route for Zhuhai airport

\begin{tabular}{ccccccc}
\hline No. & Dep airport & Dep time & Arr airport & Arr time & Seat & Price (RMB) \\
\hline Flight 3 & Xining & $8: 30$ & Zhuhai & $12: 00$ & 166 & 1320 \\
Flight 4 & Xining & $14: 00$ & Zhuhai & $17: 30$ & 166 & 1320 \\
\hline
\end{tabular}

Figure 14 Demand flow distributions affected by the new air routes. (a) Without new air routes (b) With new air routes

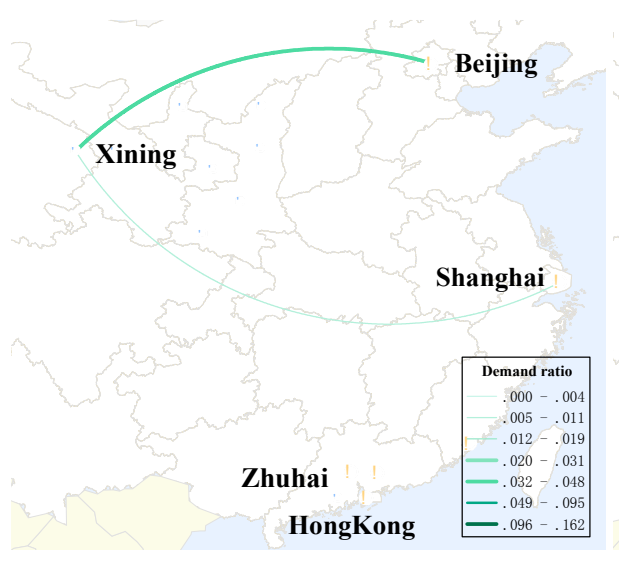

(a)

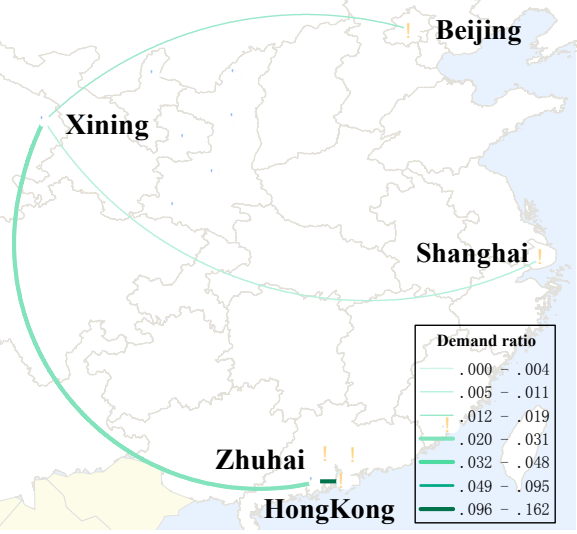

(b)

Owing the Flight 3 and Flight 4, 43.1\% and 13.7\% of the passengers who previously choose Beijing airport switch to Hong Kong airport through the air-bridge-air path. According to the results, passengers seem to be more interested in Flight 3 than Flight 4, because Flight 3 arrives earlier than Flight 4 in Zhuhai airport, it provides a longer connecting time between the domestic flight arriving at Zhuhai airport and the international flights departing from Hong Kong airport. Meanwhile, the two flights lead to a decrease in passengers' money costs of $6.7 \%$ and time costs of $5.4 \%$.

According to the results, as Xining airport is only connected to Beijing and Shanghai airports during the winter, passengers may prefer the new paths to Hong Kong airport with shorter in-flight time and lower prices. However, there are 6 flights per day from Xining to Beijing, so some passengers persist in transferring at Beijing airport because of the shorter transfer time. 


\subsection{Scenario 3: start up the new air route "Hanzhong-Zhuhai"}

Scenario 2 discussed the demand flow distribution when starting up the new air route "Xining to Zhuhai". In this scenario we will analyse the variation in the demand flow distribution by assuming adding the new air route "Hanzhong-Zhuhai". Compared to Xining airport, Hanzhong airport is a small airport near Xi'an. The flights on the new air route are listed in Table 7, and calculated passenger flow is shown in Figure 15.

Table 7 Flights on the newly added air route for Zhuhai airport

\begin{tabular}{ccccccc}
\hline No. & Dep airport & Dep time & Arr airport & Arr time & Seat & Price(RMB) \\
\hline Flight 5 & Hanzhong & $9: 30$ & Zhuhai & $12: 00$ & 166 & 960 \\
Flight 6 & Hanzhong & $14: 00$ & Zhuhai & $16: 00$ & 166 & 960 \\
\hline
\end{tabular}

Figure 15 Demand flow distributions affected by the new air routes. (a) without new air routes (b) with new air routes

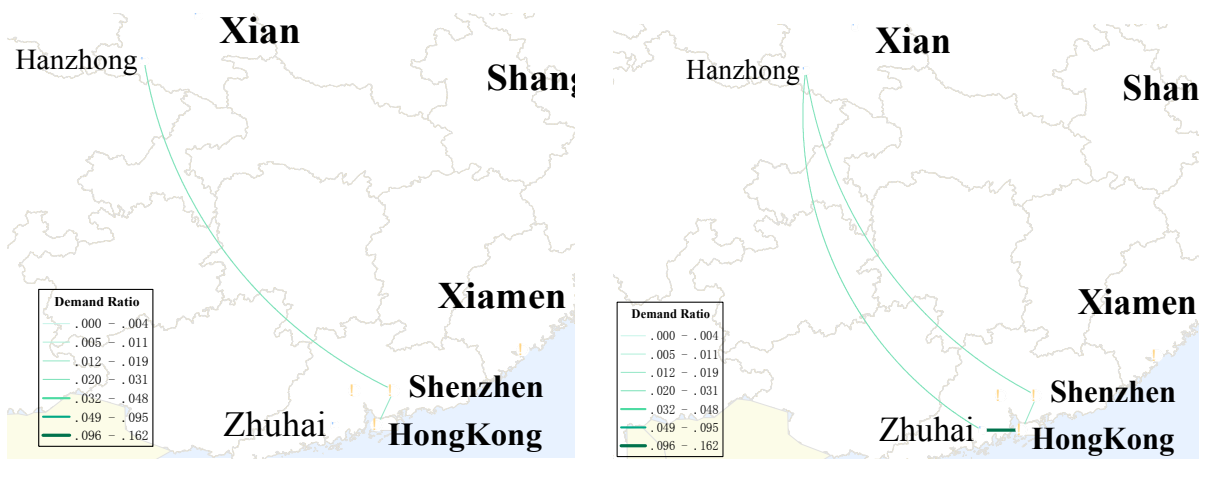

(a)

(b)

According to the variation in passenger flow distribution, only $5.2 \%$ of the passengers who previously chose Shenzhen airport switch to Hong Kong airport through the airbridge-air path. It can be seen that the passenger volume attracted by the new route "Hanzhong-Zhuhai" is much less than that attracted by the air route "Xining-Zhuhai". The reasons are two folded: there is little air travel demand in the hinterland around Hanzhong airport, and there exists strong competition from Shenzhen airport. Therefore, the small airports that have been strongly connected to Shenzhen airport are not good choices for Zhuhai airport in developing its flight network.

By comparing the effects of different strategies on developing the flight network, it can be summarized that Zhuhai should be linked to the cities which have abundant air travel demand to Southeast Asia and the new flights have to be set with proper departing times for the convenience of transfer. According to all strategies discussed above, starting up the new air route "Xining-Zhuhai" is an effective choice.

\section{Conclusions}

On the basis of the trans-strait linkage created by the Hong Kong-Zhuhai-Macao Bridge, Zhuhai airport and Hong Kong airport are collaboratively establishing an air-bridge-air 
path to capture the potential aviation market between Northwest China and Southeast Asia. To evaluate the efficiency of the path, this paper developed a path choice approach based on the NL model and a time-space network. In order to reveal the intermodal transfers within the air-bridge-air path, the path choice model was established on a timespace network. The estimated model was further used to predict the geographical distribution of passenger flow from Northwest China to Manila based on the survey data, thus calculated the incremented air travel demand which would be attracted to Hong Kong airport.

The results indicate that the path significantly improves the travel efficiency for passengers who flying from Northwest China to Southeast Asia, which may help promote the trading and tourism between the two regions under the B\&R initiative. Furthermore, with the purpose of linking Hong Kong airport closely to Northwest China, we discussed two types of strategies to improve the flight network of Zhuhai airport. They are (i) increasing the flight frequency of current air routes and (ii) starting up new air routes. The effects of these strategies were evaluated by predicting passenger flow distribution in the relevant scenarios. According to the scenario analysis results, starting up the new air route "Xining-Zhuhai" was shown to be an effective strategy, and some tips with respect to planning the new air routes were offered.

As our proposed model fixed the total air travel demand between the origins and destinations, this may influence the accuracy of the predicted demand for the air-bridgeair path. Therefore, we will try to incorporate the effects of the air-bridge-air path on the induced air travel demand between Northwest China and Southeast Asia in future works. Meanwhile, we will also focus on optimising the flight network of Zhuhai and Hong Kong airports by incorporating path choice behaviour.

\section{Acknowledgements}

This research was sponsored by the National Natural Science Foundation of China (Grant Nos. 71701094; 71431001)

\section{References}

Abdelghany, A., Abdelghany, K. and Azadian, F. (2017) 'Airline flight schedule planning under competition', Computers and Operations Research, Vol. 87, pp.20-39.

Akar, G. (2013) 'Ground access to airports, case study: port Columbus international airport', Journal of Air Transport Management, Vol. 30, pp.25-31.

Alhussein, S.N. (2011) 'Analysis of ground access modes choice King Khaled international airport, Riyadh, Saudi Arabia', Journal of Transport Geography, Vol. 19, No. 6, pp.1361-1367.

Arase, D. (2015) 'China's two silk roads initiative: what it means for Southeast Asia', Southeast Asian Affairs, No. 1, pp.25-45.

Barrat, A., Barthélemy, M. and Vespignani, A. (2005) 'The effects of spatial constraints on the evolution of weighted complex networks', Journal of Statistical Mechanics: Theory and Experiment, No. 5. Doi: 10.1088/1742-5468/2005/05/P05003.

Behrens, C. and Pels, E. (2012) 'Intermodal competition in the London - Paris passenger market: high-speed rail and air transport', Journal of Urban Economics, Vol. 71, No. 3, pp.278-288.

Bliemer, M.C. and Rose, J.M. (2011) 'Experimental design influences on stated choice outputs: an empirical study in air travel choice', Transportation Research Part A: Policy and Practice, Vol. 45, No. 1, pp.63-79. 
Bliemer, M.C., Rose, J.M. and Hensher, D.A. (2009) 'Efficient stated choice experiments for estimating nested Logit models', Transportation Research Part B: Methodological, Vol. 43, No. 1, pp.19-35.

Bowman, J.L. and Ben-Akiva, M.E. (2001) 'Activity-based disaggregate travel demand model system with activity schedules', Transportation Research Part A: Policy and Practice, Vol. 35, No. 1, pp.1-28.

Chang, Y.C. (2013) 'Factors affecting airport access mode choice for elderly air passengers', Transportation research part E: logistics and transportation review, Vol. 57, pp.105-112.

Chiambaretto, P., Baudelaire, C. and Lavril, T. (2013) 'Measuring the willingness-to-pay of air-rail intermodal passengers', Journal of air transport management, Vol. 26, pp.50-54.

D'Alfonso, T., Jiang, C. and Bracaglia, V. (2016) 'Air transport and high-speed rail competition: environmental implications and mitigation strategies', Transportation Research Part A: Policy and Practice, Vol. 92, pp.261-276.

D'Alfonso, T., Jiang, C. and Wan, Y. (2013) 'Airport pricing, concession revenues and passenger types', Journal of Transport Economics and Policy (JTEP), Vol. 47, No. 1, pp.71-89.

Drabas, T. and Wu, C.L. (2013) 'Modelling air carrier choices with a segment specific cross nested Logit model', Journal of Air Transport Management, Vol. 32, pp.8-16.

Duthie, J.C., Unnikrishnan, A. and Waller, S.T. (2011) 'Influence of demand uncertainty and correlations on traffic predictions and decisions', Computer-Aided Civil and Infrastructure Engineering, Vol. 26, No. 1, pp.16-29.

$\mathrm{Fu}$, X., Lam, W.H. and Chen, B.Y. (2014) 'A reliability-based traffic assignment model for multimodal transport network under demand uncertainty', Journal of Advanced Transportation, Vol. 48, No. 1, pp.66-85.

Gillen, D., Hasheminia, H. and Jiang, C. (2015) 'Strategic considerations behind the network regional airline tie ups - a theoretical and empirical study', Transportation Research Part B: Methodological, Vol. 72, pp.93-111.

Hess, S. (2007) 'Posterior analysis of random taste coefficients in air travel behaviour modelling', Journal of Air Transport Management, Vol. 13, No. 4, pp.203-212.

Hess, S. and Polak, J.W. (2005) 'Mixed logit modelling of airport choice in multi-airport regions', Journal of Air Transport Management, Vol. 11, No. 2, pp.59-68.

Hsiao, C.Y. and Hansen, M. (2011) 'A passenger demand model for air transportation in a huband-spoke network', Transportation Research Part E: Logistics and Transportation Review, Vol. 47, No. 6, pp.1112-1125.

Huang, Y. (2016) 'Understanding China's belt and road initiative: motivation, framework and assessment', China Economic Review, Vol. 40, pp.314-321.

Hussain, N., Wong, C., Carter, M., Kwan, S. and Mak, T.W. (2011) 'Hong Kong Zhuhai Macao Link', Procedia Engineering, Vol. 14, pp.1485-1492.

Ishii, J., Jun, S. and Van Dender, K. (2009) 'Air travel choices in multi-airport markets', Journal of Urban Economics, Vol. 65, No. 2, pp.216-227.

Jiang, C. and Zhang, A. (2014) 'Effects of high-speed rail and airline cooperation under hub airport capacity constraint', Transportation Research Part B: Methodological, Vol. 60, pp.33-49.

Jiang, C. and Zhang, A. (2016) 'Airline network choice and market coverage under high-speed rail competition', Transportation Research Part A: Policy and Practice, Vol. 92, pp.248-260.

Jiang, C., D'Alfonso, T. and Wan, Y. (2017) 'Air-Rail cooperation: partnership level, market structure and welfare implications', Transportation Research Part B: Methodological, Vol. 104, pp.461-482.

Li, K.X., Jin, M., Qi, G., Shi, W. and Ng, A.K. (2018) 'Logistics as a driving force for development under the belt and road initiative - the Chinese model for developing countries', Transport Reviews, Vol. 38, No. 4, pp.457-478.

Li, X., Jiang, C., Wang, K. and Ma, J. (2018) 'Determinants of partnership levels in air-rail cooperation', Journal of Air Transport Management, Vol. 71, pp.88-96. 
Li, Z.C. and Sheng, D. (2016) 'Forecasting passenger travel demand for air and high-speed rail integration service: a case study of Beijing-Guangzhou corridor, China', Transportation Research Part A: Policy and Practice, Vol. 94, pp.397-410.

Liu, X., Zhang, K., Chen, B., Zhou, J. and Miao, L. (2018) 'Analysis of logistics service supply chain for the one belt and one road initiative of China', Transportation Research Part E: Logistics and Transportation Review, Vol. 117, pp.23-39.

Liu, Z., Wang, T., Sonn, J.W. and Chen, W. (2018) 'The structure and evolution of trade relations between countries along the Belt and Road', Journal of Geographical Sciences, Vol. 28, No. 9, pp.1233-1248.

Lo, H.K., Yip, C.W. and Wan, K.H. (2003) 'Modeling transfer and non-linear fare structure in multi-modal network', Transportation Research Part B: Methodological, Vol. 37, No. 2, pp.149-170.

Loo, B.P. (2008) 'Passengers' airport choice within multi-airport regions (MARs): some insights from a stated preference survey at Hong Kong international airport', Journal of Transport Geography, Vol. 16, No. 2, pp.117-125.

Shao, Z.Z., Ma, Z.J., Sheu, J.B. and Gao, H.O. (2018) 'Evaluation of large-scale transnational high-speed railway construction priority in the belt and road region', Transportation Research Part E: Logistics and Transportation Review, Vol. 117, pp.40-57.

Shuai, C. (2018) Zhuhai airport and Hong Kong airport will operate coordinated flights in the future, Da Gong Website. Available online at: http://www.takungpao.com/news/ 232108/2018/1121/208441.html?from=singlemessage\&isappinstalled $=0$ (assessed on 15 June 2019).

Sismanidou, A., Tarradellas, J., Bel, G. and Fageda, X. (2013) 'Estimating potential long-haul air passenger traffic in national networks containing two or more dominant cities', Journal of Transport Geography, Vol. 26, pp.108-116.

Sit, V.F. (2003) 'Forging Asia's global transpark in the pearl river delta at Zhuhai', Chinese Geographical Science, Vol. 13, No. 4, pp.300-309.

State Information Centre (2018) Belt and Road Big Data Report 2018, The Commercial Press.

Steinzen, I., Gintner, V., Suhl, L. and Kliewer, N. (2010) 'A time-space network approach for the integrated vehicle-and crew-scheduling problem with multiple depots', Transportation Science, Vol. 44, No. 3, pp.367-382.

Tang, C.H., Yan, S. and Chen, Y.H. (2008) 'An integrated model and solution algorithms for passenger, cargo, and combi flight scheduling', Transportation Research Part E: Logistics and Transportation Review, Vol. 44, No. 6, pp.1004-1024.

Tong, L., Zhou, X. and Miller, H.J. (2015) 'Transportation network design for maximizing spacetime accessibility', Transportation Research Part B: Methodological, Vol. 81, pp.555-576.

Totamane, R., Dasgupta, A. and Rao, S. (2012) 'Air cargo demand modeling and prediction', IEEE Systems Journal, Vol. 8, No. 1, pp.52-62.

Tsui, K.W.H., Yuen, A.C.L. and Fung, M.K.Y. (2018) 'Maintaining competitiveness of aviation hub: empirical evidence of visitors to China via Hong Kong by air transport', Current Issues in Tourism, Vol. 21, No. 11, pp.1260-1284.

Wadud, Z. (2015) 'Imperfect reversibility of air transport demand: effects of air fare, fuel prices and price transmission', Transportation Research Part A: Policy and Practice, Vol. 72, pp.16-26.

Walcott, S.M. and Fan, Z. (2017) 'Comparison of major air freight network hubs in the US and China', Journal of Air Transport Management, Vol. 61, pp.64-72.

Wan, Y., Jiang, C. and Zhang, A. (2015) 'Airport congestion pricing and terminal investment: effects of terminal congestion, passenger types, and concessions', Transportation Research Part B: Methodological, Vol. 82, pp.91-113.

Wang, K., Tsui, K.W.H., Liang, L. and Fu, X. (2017) 'Entry patterns of low-cost carriers in Hong Kong and implications to the regional market', Journal of Air Transport Management, Vol. 64, pp.101-112. 
Wei, W. and Hansen, M. (2006) 'An aggregate demand model for air passenger traffic in the huband-spoke network', Transportation Research Part A: Policy and Practice, Vol. 40, No. 10, pp.841-851.

Xia, W., Jiang, C., Wang, K. and A. Zhang (2019) 'Air-rail revenue sharing in multi-airport system: effects on traffic and social welfare', Transportation Research Part B: Methodological, Vol. 121, pp.304-319.

Yan, S., Chen, S.C. and Chen, C.H. (2006) 'Air cargo fleet routing and timetable setting with multiple on-time demands', Transportation Research Part E: Logistics and Transportation Review, Vol. 42, No. 5, pp.409-430.

Yang, C.W. and Liao, P.H. (2016) 'Modeling the joint choice of access modes and flight routes with parallel structure and random heterogeneity', Transportation Research Part E: Logistics and Transportation Review, Vol. 95, pp.19-31.

Yang, C.W., Lu, J.L. and Hsu, C.Y. (2014) 'Modeling joint airport and route choice behavior for international and metropolitan airports', Journal of Air Transport Management, Vol. 39, pp.89-95.

Yu, S., Yang, Z. and Yu, B. (2017) 'Air express network design based on express path choices Chinese case study', Journal of Air Transport Management, Vol. 61, pp.73-80 